conclusion of Dr. C. E. Jung's Contributions to the Geography of Victoria ; an important paper, with map, on the Chinese province of Kwang-tung and its people, by Herr J. Nacken; another on D'Albertis' New Guinea Exploration, with map of the Fly River; with papers on the Exploration of the Ogowé, Nordenskjöld's Voyage in the Vega, and Dr. Behm's montbly summary. Thus it seems that Dr. Behm, the new editor, is likely to maintain the reputation and value of this, the most important geographical organ.

THE October Bolletina of the Italian Geographical Society contains a short account of the Progress of the Italian African Expedition, and letters from Lieut. Bove who accompanies Prof. Nordenskjöld in his North-East Passage Expedition. In the Bulletin of the Paris Society is a translation of the Grand Duke Nicholas's paper on the Shortest Route for a Railway to Central Asia ; a paper by M. L. Simonin on the Indians of the United States, with a map showing the Indian reservations; the continuation of Dr. Decugis' Account of his Journey in Morocco; a long article by the Abbé Ménager on Guinea, besides shorter papers on a Uniprojectional Atlas, and the Rio Casca of Peru.

The Portuguese African expedition, under Serpa Pinto, which left Benguela a year ago, reached Bihé in March last, and was to enter the unknown interior in two divisions. The Lisbon Creographical Society are moving Government for a scientific expedition into Portuguese Senegambia.

ON SOME IMPROVED METHODS OF PRO. DUCING AND REGULATING THE ELECTRIC LIGHT

$\triangle$ MONG the manifold functions which the elementary substance carbon performs in organic nature, not the least important is that by which it becomes the great source of artificial illumination, whether derived from oils, coal gas, or from coke rendered incandescent by the action of powerful electric currents. Since the time when Davy first produced the voltaic arc, between two points of wood charcoal, through which was transmitted the current from the great battery of 2,000 plates belonging to the Royal Institution, many experiments have been made to determine the best kinds of carbon for developing the electric light. The carbon which, until recently, was most commonly employed for this purpose, is obtained from the sides of gas retorts, where it accumulates in the form of coke during the destructive distillation of coal. The shells of coke from the retort are sawn up into pencils from one quarter to half an inch square, and from six to nine inches in length. Although very good results are obtained from carbon of this kind, it is a difficult material to work on account of its hardness, and it sometimes contains impurities which interfere with its conductivity. It is also liable to fracture when suddenly heated by the transmission of powerful electric currents. These defects have led to the introduction in electric lighting of artificial carbon, composed of powdered coke and lampblack, formed into a paste with molasses and gum. This material is pressed into cylindrical forms, and subjected for a given time to a high temperature in a special furnace. The manufacture of these carbon pencils has attained great perfection in the hands of Carré, of Paris, and they can be made into perfectly straight and cylindrical forms of from two to sixteen millimetres in diameter, and half a metre in length.

When the electric light is to be used for illumination, it is necessary that it should be as continuous as other modes of lighting. For this purpose not only should the current

${ }^{r}$ Paner reat by Mr. Henry Wilde at the Manches:er Literary and Paner reat by Mr. Henry
Philosophical Society, October 29 . be regular in its action, but the distance between the carbor points must not alter, which necessitates the use of some arrangement for bringing them nearer together in proportion as they are consumed. Much ingenuity has been displayed by electricians in solving this problem, and the automatic contrivances invented by Staite, Duboscq, Foucault, Serrin, and others, leave little to be desired in regard to the steadiness of the light, when the regulators are in good order, and in the hands of intelligent operators. All automatic instruments, however, from the delicacy of their mechanism, are liable to derangement, and their action is not easily understood by persons not having a special knowledge of their construction. To obviate the objection to the use of such instruments by unskilled attendants, I devised, a few years since, a regulator for use on H.M.'s ships of war, to be actuated by hand. In this arrangement the carbons are made to approach and separate from each other by means of a right and left-handed screw connected with the carbon holders. Each of the screws, with its carbon holder, can be actuated independently of the other, for the purpose of adjusting the points of the carbons to the proper focus of the optical apparatus used in connection with it. The regulator, with its carbon points, is placed in the focus of a dioptric lens, which parallelises the divergent rays of light into a single beam of great intensity. The lens with the regulator is pivoted horizontally and vertically on the top of a short iron column, fixed on $a$ raised platform above the deck, and the beam of light may be projected upon any distant object within its range. This special application of the electric light, however, as will be seen, requires the frequent adjustment of the carbons by the operator, but as he is always required to be in attendance to manipulate the projector, no inconvenience is experienced through the absence of the automatic arrangement. This method of regulating the electric light has now been in use in the Royal Navy for more than three years, and has proved very satisfactory.

Simultaneously with the progress of improvements in the mechanism for regulating the electric light, experiments have been made with the object of dispensing with the regulator altogether. The most recent, as well as the most successful, of these attempts has been made by M. Jablochkoff, a Russian inventor. In the specification of his letters patent of 1877 he proposes to place the carbons side by side (as had been previously proposed by Werdermann in I 874), and to separate them by an insulating substance to be consumed along with the carbon. The inventor states that the insulating substance for separating the carbons may be kaolin, glass of various kinds, alkaline earths, and silicates, which he prefers to apply in the form of powder rammed into an asbestos cartridge-case containing the carbons. A powder which the inventor found serviceable consists of one part lime, four parts sand, and two parts talc. These materials are rammed into the cartridge-case surrounding and separating two parallel sticks of carbon placed in the case, at a little distance apart. One of the carbons is made thicker than the other to allow for its more rapid waste. The lower ends of the carbons are inserted into pieces of copper tube or other good conductor, separated from one another by asbestos, and the ends of the tubes are pinched between two limbs of a screw vice, con: nected respectively to the conducting wires. This combination of carbons and insulating materials the inventor terms an electric candle, which, when mounted on a stand or candle-stick, has the appearance of the Roman candle of pyrotechnists. The inventor further states that the heat produced by the electricity fuses the material between the carbons and dissipates it; and the freedom of the passag afforded by the fused material to the electric current permits the subdivision of the light by placing several lamps in the course of one electric circuit. It is also stated that the construction of the candle may be varied; and, among the forms described, is one in which the carbons, instead of being contained in a cartridge case, 
are separated by a partition of kaolin or other similar insulating material.

I have thought it well to describe, as nearly as possible in the words of the inventor, the electric candle, which is now the subject of so much attention in its application to electric lighting; so that its relation to what follows may be more clearly perceived. A remarkable peculiarity of the direct current in electric lighting is that of its consuming the positive carbon at twice the rate of the negative one, and while the negative carbon is a pointed cone, like that of a pencil, the positive pole takes the form of a hollow cavity or crater.

M. Jablochkoff's early experiments'seem to have been made with the direct current, and hence his carbons are described as being of unequal thickness, in order that the positive and negative carbons of the candle might be evenly consumed. When the alternating current is used for producing electric light both carbons are of the same thickness, and are consumed at an equal rate, and both points terminate in regular cones. This property of the alternating current, besides other advantages, always maintains the luminous point in the focus of any optical apparatus used in connection with it, that is, when the carbons are placed end to end, as I had occasion to point out in a former paper read before the Society in 1873 , on an electro-magnetic induction machine for producing alternating currents.

M. Jablochkoff, in the course of his experiments, would appear to have met with some difficulties in adapting the direct or continuous current to a system of lighting with his electric candles, and now uses the alternating current for this purpose. The candle has also been simplified by substituting a slip of plaster of Paris for the cartridge and partition of kaolin formerly employed.

To produce the alternating currents, however, to supply a number of lights, it was found necessary to employ powerful electro-magnetic induction machines, excited by the currents from other smaller machines, according to the principles laid down in my paper read before the Royal Society, and published in the Philosophical Trans. actions of 1867 . From sixteen to twenty lights are produced from one of these electro-magnetic machines, each light absorbing about one-horse power.

The system of electric lighting above described would now seem to be definitely established in some places as a substitute for gas, and visitors to the French capital during the present summer will have been struck with the fine effects produced in the avenues and squares where the light is displayed.

My connection with the history of this system of lightin: placed me in a position to make some experiments with the Jablochkoff candle, and led to the discovery of the following facts. One of the conditions necessary for producing a constant light from the candle, in its most recent form, was that the quantity and intensity of the alternating current should be such that the carbons consume at a rate of from four to five inches per hour. If the electric current were too powerful, the carbons became unduly heated, and presented additional resistance to the passage of the current; the points at the same time lost their regular conical form. If, on the other hand, the current were too weak, the electric arc played about the points of the carbons in an irregular manner, and the light was easily extinguished by currents of air.

In the course of these experiments I was struck with the apparently insignificant part which the insulating material played in the maintenance of the light between the carbon points; and it occurred to me to try the effect of covering each of the carbons with a thin coating of hydrate of lime, and mounting them parallel to each other in separate holders, and without any insulating material between them. The use of the lime covering was intended to prevent the light from travelling down the contiguous sides of the carbons. On completing the electric circuit the light was maintained between the two points, and the carbons were consumed in the same regular manner as when the insulating material had been placed between them.

Two plain cylindrical rods of carbon three-sixteenths of an inch in diameter and eight inches long, were now fixed in the holders parallel to each other, and one-eighth of an inch apart. The strength of the alternating current was such that it would fuse an iron wire 0.025 of an inch in diameter and eight feet in length. On establishing the electric current through the points of the carbons by means of a conducting paste composed of carbon and gum, the light was produced, and the carbons burnt steadily downwards as before.

Four pairs of naked carbons mounted in this manner were next placed in series in the circuit of a four-light machine, and the light was produced from these carbons simultaneously, as when the insulating material was used between them. The light from the naked carbons was also more regular than that from the insulated ones, as the plaster of Paris insulation did not always consume at the same rate as the carbons, and thereby obstructed the passage of the current. This was evident from the rosy tinge of the light produced by the rolatilisation of the calcium simultaneously with the diminution of the brilliancy of the light from the carbons.

The only function, therefore, which the insulating mate rial performs in the electric candle, as shown by these experiments, is that it conceals the singular and beautiful property of the alternating current to which $I$ have directed attention.

As I have already said, the strength of the alternating current must bear a proper proportion to the diameter of the carbons used, and when a number of such lights are required to be produced in the same circuit, the quantity and property of the current will remain constant, while the tension-will require to be increased with the number of lights.

This simple method of burning the carbons will, I believe, greatly further the development of the electric light, as the carbons can be used of much smaller diameter than has hitberto been possible. They may also be of any desired length, for as they are consumed they may be pushed up through the holders without interrupting the light. One of these developments will be a better method of lighting coal and other mines. In this application the alternating currents or waves from a powerful electro-magnetic induction machine may be used for generating, simultaneously, alternating secondary cur rents or waves in a number of small induction coils, placed in various parts of the mine. The light may be produced in the secondary circuits from pairs of small carbons inclosed in a glass vessel having a small aperture to permit the expansion of the heated air within. Diaphragms of wire gauze may be placed over the aperture to prevent the access of explosive gas. By generating secondary currents or waves without interrupting the continuity of the primary circuit, the contact-breaker is dispensed with, and the subdivision of the light may be carried to a very great extent.

\section{A STUDY IN MAGNETISM}

THE name of Faraday will go down to posterity foremost amongst the names of the scientific men of this century, for the simple comprehensiveness and original beauty of his researches in electricity and magnetism; chiefly, perhaps, for his discovery of magnetoelectricity - the kind of electricity that can be induced in conductors which are caused to pass near magnets. Those who have carefully read Faraday's works know how he was led to this discovery by the conception he had formed of magnetic force. Until his time magnetic 